\title{
Felicitas Holzer
}

\section{International Patent Regimes and Access to Medicines: Is the Health Impact Fund an Effective Solution?}

Der Zugang der Entwicklungsländer zu den Errungenschaften des medizinischen Fortschritts ist vielfach defizitär. Besondere Probleme bereitet dabei der Zugang zu patentgeschützten Arzneimitteln. Das Spannungsverhältnis zwischen den internationalen Regeln des Patentschutzes einerseits und den pharmazeutischen Bedürfnissen der Entwicklungsländer andererseits ist das Thema des Beitrags von Holzer. Schwerpunkt ist die Auseinandersetzung mit den rechtspolitischen Vorschlägen zur Lösung der Problematik. OdW ist für Diskussionsbeiträge $\mathrm{zu}$ diesem wichtigen wissenschaftspolitischen Thema offen.

Dem Journal of Science, Humanities and Arts (josha. org) danken wir für die Genehmigung der Übernahme in OdW.

\section{Introduction}

Patents are currently the most common mechanism to stimulate pharmaceutical innovation. They are considered an efficient allocation mechanism and a system in which fewer resources are squandered. ${ }^{1}$ Patents are of importance for pharmaceutical companies, since innovation is expensive with developing costs per new drug at more than 2 billion U.S. Dollars. ${ }^{2}$ In 1995, members of the World Trade Organization (WTO) signed the agreement on Trade Related Aspects of Intellectual Property Rights (TRIPS) to standardize patent rights in an international context. ${ }^{3}$ The trade agreement entails strict patent protection laws, i.e. a market exclusivity for patented drug over a period of at least 20 years. ${ }^{4}$ One of the main incentives to design the TRIPS agreement was to create a reward mechanism for pharmaceutical compa-

1 Hollis (2008: 124-125). All risk of R\&D costs is efficiently imposed on the pharmaceutical company that develops new drugs.

2 DiMasi et al. (2014). These costs include marketing approval, $\mathrm{R} \& \mathrm{D}$, out-of-the pocket and time costs.

3 WTO (2001), Hollis (2008: 124).

4 Ravvin (2008: 110), Hollis (2008: 124). The TRIPS agreement was fully implemented by most of the WTO member states in 2005.

5 Ravvin (2008), Pogge (2009: 543-546), Buchanan et al. (2011: $307-$ 310, 131), see Pogge (2009).

6 Pogge $(2008,2009)$.

$7 \quad$ Faunce and Nasu (2008: 146).

8 Pogge (2005, 2008, 2008b, 2009) argues that also poor patients from affluent countries cannot afford expensive medicines. nies in order to recover costs, to make profits and importantly, to promote research and development (R\&D) for diseases that affect developing nations. ${ }^{5}$

However, the adoption of the TRIPS agreement exacerbated two problems that are persistent in the discussion about essential medicines for the global poor. ${ }^{6}$

Access to medicines: First, there is a distribution problem of existing innovations. As Thomas Faunce and Hitoshi Nasu put it, "the moral and practical problem of how poor people will continue to gain affordable access to medicines is one of the most pressing issues currently confronting humanity". 7 Oftentimes, essential medicines are not accessible for poor patients, since pharmaceutical companies set high prices for drugs under the current patent regime. ${ }^{8}$ After the implementation of the TIRPS agreement, the generic industry for new drugs was effectively shut down in developing countries due to the strict patent protection on a global scale. Thus, the accessibility of new innovations under the TRIPS regime has been shifted beyond the twenty-year protection of patents. Thomas Pogge argues that in consequence, an even higher percentage of the global poor is nowadays excluded from drug use than during the pre-TRIPS era. ${ }^{9}$

Lack of R\&D for neglected diseases: Second, under high price patent regimes, in which drugs are sold under a monopoly ${ }^{10}$, most R\&D is dedicated to diseases predominant in developed nations where the purchasing power for expensive pharmaceuticals is the highest. ${ }^{11}$ Hence, due to a lacking market in developing countries, pharmaceutical companies do not develop a sufficient amount of essential medicines that would be life-saving for type II and III diseases like tuberculosis, HIV/AIDS and tropical diseases. ${ }^{12}$ Among other factors, this imbalance in global R\&D finds expression in the "10/90 gap" - only 10

$9 \quad$ Pogge (2008: 73-76, 2009: 543-546).

10 Monopoly prices are usually associated with inefficient market solutions from a macroeconomic standpoint. Baker (2004: 2-3) estimates that for every dollar spent on R\&D in the pharmaceutical sector, one dollar is lost in deadweight losses - potentially benefits to consumers that are not realized due to high prices.

11 See Davis (1995), Hollis (2008), Pogge (2008), Pogge (2009), Ridley and Grabowski (2006).

12 The World Health Organization (2012:1) defines type I diseases as incident in both rich and poor countries with large numbers of vulnerable populations, and type II diseases as more substantially incident in poor countries. See Buchanan et al. (2011:307), see WHO (2006). 
per cent of the global R\&D is devoted to diseases that account for 90 percent of the global disease burden. ${ }^{13}$ Likewise, there is a bias towards symptom relieving drugs under the current patent regime. This means that profits for pharmaceutical companies depend on the number of treatments sold - which increases with the treatment of symptoms - and not necessarily on the health impact on the global burden of disease. ${ }^{14}$

There have been various attempts to overcome the outlined weaknesses of international patent regimes during the past decade. One of the most prominent proposals by Thomas Pogge and Aidan Hollis is the Health Impact Fund (HIF). ${ }^{15}$ The HIF is designed to address the essential medicines problem while preserving the current patent regime. The reform proposal of the HIF is based on Pogge's defence of a global health reform. Notably, he pursues a human rights approach to justify the urgent need for alternatives to the current patent regime that, in his view, violates the human right to health by depriving the poor. ${ }^{16}$ According to article 25 of the Universal Declaration of Human Rights, everyone has the right to a standard of living adequate for health and well-being which also includes medical care. Likewise, the World Health Organization defines the right to health as enjoyment of the highest attainable standard of physical and mental health, which is embedded in international and domestic legal systems. ${ }^{17}$ While legal obligations of granting the right to health were historically imposed on national duty-bearers, broader theories of justice have been evolving during the past 15 years and encompass a global approach to health obligations. ${ }^{18}$ For instance, Pogge gives an historical account for a duty of the affluent countries to actively improve the health situation of the global poor. He infers this duty from the fact that the developed world has been responsible for the current unjust global order. ${ }^{19}$ Nevertheless, the human rights approach may be more commonly considered a robust ethical framework which is rooted in the strong belief that there is a social value for the respect for human dignity and conceptualized as an international human rights norm. ${ }^{20}$

As a matter of stipulation with the scope of this essay, I will not dwell on Pogge's human rights approach or his historical argument for a global health reform as philosophical foundations for the HIF. Likewise, I will not respond to the libertarian defence of property rights. ${ }^{21}$ In this essay, I will discuss the design of the HIF and problems that arise with respect to its practical implementation. In this regard, I will follow the main line of argument in the literature on the HIF.

After reconstructing the design of the HIF alongside other recent approaches to improve the health of the global poor, I will critically scrutinize the expected effectiveness of the HIF in terms of its health impact on the global burden of disease. I will then give a general overview on the practical problems that the HIF poses and reconstruct the main points of criticism by Jorn Sonderholm, Allen Buchanan et al., and Michael Selgelid. ${ }^{22}$ Subsequently, I will discuss the last mile problem in more detail. The last mile problem addresses the practical problem of lacking infrastructure in low-income countries and constitutes a major obstacle to the accessibility of medicines. ${ }^{23}$ I will build upon Sonderholm who reformulates the last mile problem as collective choice problem. However, my aim is to go beyond Sonderholm's critique by embedding the last mile problem into the broader context of global poverty traps. More precisely, I will argue that a solution to the last mile problem would entail the access to pharmaceuticals and the access to information, education, technology and economic participation, which are crucial factors for the distribution and accessibility of drugs on the last mile. As a result, I will argue that the HIF can potentially contribute, but not fully solve the last mile problem and consequently, the access to medicines problem persists under the HIF.
13 Luchetti (2014: 731)

14 Ravvin (2008:112), Faunce and Nasu (2008), see Hilary (2001), see Farmer (2004).

15 Hollis $(2005,2007,2008)$, Pogge $(2005,2008,2009)$.

16 Pogge (2009: 554, 2005, 2005b).

17 The Universal Declaration of Human Rights (1948) art. 25 (1), WHO (2008), International Covenant on Economic, Social and Cultural Rights (1966) art. 12, Hunt (2008: 1-9).

18 See Clapham (2006), Pogge (2002, 2005, 2005b).

19 See Pogge (2002).

20 See Sen (1999), see McDonald (2006), Pogge (2005, 2005b, 2009). Even libertarians like Nozick (1974: 178-182), acknowledge the limits of private property in the light of human rights violations by saying that those in control of the remaining resources must not deprive people from essential goods. See Exdell (1977: 144-145), see Gordon (1992).

21 In his philosophical foundation, Pogge (2009: 559-566) discusses the libertarian appeal to intellectual property rights. Pogge (2009: 364-365) denies the moral permissibility of intellectual property rights by arguing that intellectual property suppresses the poor people's freedom to use essential resources.

22 Sonderholm (2010), Buchanan et al. (2011), Selgelid (2008)

23 Sonderholm (2010: 171). Even if a drug is available on the local market at cheap prices, a lack of infrastructure can lead to delivery problems over the last mile. 


\section{The Health Impact Fund in the context of other approaches to improve the health situation of the global poor}

States, international organizations and NGOs have made various attempts to improve the health situation of the global poor. Most notably, the Doha Declaration on the TRIPS Agreement and Public Health states that trade agreements should be interpreted and implemented to protect public health and to promote access to medicines. ${ }^{24}$ Push-mechanisms have historically been the primary ways to promote R\&D for socially desirable but unprofitable medicines. ${ }^{25}$ Push-mechanisms reduce the costs of R\&D for researchers by providing funding up front. Governments and other funding bodies usually provide resources for research through grants. More recently, other push-strategies have been emerging like Public Private Partnerships and international health programs. ${ }^{26}$ In contrast to pushmechanisms, pull-mechanisms give incentives to profit-seeking innovators to develop pharmaceuticals that are aligned to the social needs. ${ }^{27}$ For instance, Advances Market Commitments are committed to reward payments for medicines that meet certain criteria. ${ }^{28}$

However, there are several flaws related to these current attempts to improve $\mathrm{R} \& \mathrm{D}$ for neglected diseases. Push-mechanisms, for instance, support publicly funded projects that often lead to unsuccessful R\&D. Likewise, funding bodies may not be the most efficient agents to accurately determine successful projects. ${ }^{29}$ Furthermore, push-mechanisms eventually lead to drugs that are sold at monopoly prices, since late-stage R\&D is mostly funded by private companies. ${ }^{30}$ In turn, Hollis points out that Advanced Market Commitments are actually efficient mechanisms because private companies bear the full costs of R\&D. However, at the same time, they exhibit a too narrow scope for product development. ${ }^{31}$ Hence, current push- and pull-mechanisms, much the same as the TRIPS patent system, do not sustainably solve the two aspects of the essential medicines problem: the suboptimal access to life-saving drugs due to monopoly pricing and the limited $\mathrm{R} \& \mathrm{D}$ resources for drugs that would be of benefit to the global poor. ${ }^{32}$

The reform proposal by Hollis and Pogge is a pull mechanism that addresses both aspects of the essential medicines problem. The HIF offers a second patent option alongside the current international patent regime. ${ }^{33} \mathrm{Un}$ der the proposed HIF, pharmaceutical companies that bring new drugs to market have the option to either set monopoly prices under patents or to register new medicines with the HIF. The company could patent a HIF-registered drug in any country, but would be obliged to sell it everywhere during the reward period of 10 years at a determined price, ideally at production costs, and to offer a free license of the relevant technology to manufacture the drug after the reward period. ${ }^{34}$ Reward payments would have to match the expected profit the firm would make by setting monopoly prices. Furthermore, reward payments would be based on the global health impact of the product, which could be assessed by quantitative methods to measure the reduction in the global burden of disease like Quality-Adjusted Life Years (QALYs), ${ }^{35}$ a standardized measure to assess health interventions. ${ }^{36}$ Hollis proposes two options to determine the amount of money that would be paid to the innovator. Either the price per incremental QALY would be fixed which would leave the budget of the fund indeterminate, or a total amount of funding for all innovators would be fixed in advance leaving the reward payment per QALY variable. ${ }^{37}$ Moreover, Hollis' and Pogge's reform proposal aims to provide a just allocation mechanism of costs to finance the HIF. Developed nations should bear most of the costs needed to build and maintain the HIF.

According to Pogge, the HIF could be built if developed nations spent around 70 billion U.S. Dollars annually which would make up only 0.27 per cent of the ag-
24 WTO (2003), paragraph 1,4,7; see Faunce and Nasu (2008).

25 Ravvin (2008: 115-117)

26 For example, projects by the International AIDS Vaccine Initiative or the Global Alliance for Tuberculosis Drug Development (2007) or the "Treating 2 Million by 2005" by the World Health Organization to target AIDS and Malaria (WHO 2003: 4-5, 24), Päivänsalo (2009: 101-102).

27 Ravvin (2008:117), see Hollis (2006)

28 Hollis (2008: 125-126), see Kremer and Glennerster (2004: Ch.7), see Word Bank (2006). Advanced Market Commitments are particularly used to incentivize R\&D for vaccines.

29 See Buchanan et al. (2011), WHO (2012), Hsu and Schwartz (2007: 26), Pogge (2008: 24), see Hollis (2007), Johnston and Wasunna (2007).
30 Ravvin (2008: 111-112, 115)

31 Hollis (2008: 125-126).

32 Ravvin (2008: 115-117).

33 Pogge (2005, 2008, 2009), Hollis (2008).

34 Hollis (2008: 127).

35 The health impact could be also measured in DALYs (DisabilityAdjusted Life Years), using disabilities as weight for burden of disease. According to Hollis (2008: 128-129), DALYs are the less appealing measure. However, Selgelid (2008: 138) argues that the DALY approach may be preferable for the HIF, since the relieffrom the burden of disease is measured.

36 See Gold et at. (2002).

37 Hollis (2008: 127). 
gregate gross national income. ${ }^{38}$ Hollis and Pogge consider the increased spending by the affluent countries as realistic option for prudential reasons: First, prices for pharmaceuticals would also be considerably lower in developed countries. ${ }^{39}$ Second, Pogge states that a "free ride" for developing countries on pharmaceutical research could show good-will of the affluent countries and enable the developing world to respond more effectively to publichealth problems. ${ }^{40}$ According to Pogge, the HIF registration system would be superior to the current status quo because it consists of an additional patent system that rewards R\&D based on the health impact of new drugs. The health impact promises to be high when a new drug targets a large number of diseases like malaria, AIDS/HIV, tuberculosis and other tropical diseases that primarily affect the developing world. Thus, the HIF would incentivize research for diseases that currently impose a high burden across the world and for which there are only few treatment alternatives available. ${ }^{41}$ Furthermore, the HIF would be more efficient than common push-mechanisms because only successful innovation would be rewarded. ${ }^{42}$ Likewise, the reward system correspondent to the health impact would generate incentives to sell the drug cheaply in order to reach more patients, and to encourage other companies to copy and sell the drug. This would substantially contribute to improve the access to medicine problem for the global poor. $^{43}$

\section{General critique and limits to the practical implementation of the HIF}

Several critiques of Hollis' and Pogge's reform proposal address the practical issues of its implementation. Faunce and Nasu, Ravvin and Hollis himself argue that the HIF would be prone to firms that exaggerate the health impact of new drugs under the HIF. ${ }^{44}$ Hence, useful resources that could be spent on $\mathrm{R} \& \mathrm{D}$, the administration of the HIF and the assessment of the health impact would have to be spent on a control system to fight corruption. ${ }^{45}$ Furthermore, Buchanan et al. criticize two implicit assumptions of the HIF model which they call funding and reliability assumption. First, to address the funding assumption, Buchanan et al. give historical evidence that most publicized funding commitments in the affluent world have not been met in practice. Thus, pharmaceutical companies would rely less on the payment commitment by the HIF than on the current patent system. Also, providing public funding to private companies is politically unpopular. ${ }^{46}$ In the same line, Faunce and Nasu as well as Sonderholm question the Pogge's suggestion that affluent countries would bear an annual price tag of 70 billion U.S. Dollars when it remains unclear whether the developed world benefits from the HIF or not. ${ }^{47}$ Second, regarding the reliability assumption, companies would have to rely on fair rewards that cover $\mathrm{R} \& \mathrm{D}$ expenses and assure equal profits compared to the ordinary patent registration. According to Buchanan et al., it remains difficult to implement reliable measurements for the health impact of drugs on the global burden of disease, in particular when diseases are multi-factorial or treated with several drugs. ${ }^{48}$ Selgelid similarly points out that despite the progress in the global disease burden (GDB) research, measurement systems like those ones using QALYs or DALYs are weakest in developing countries where they would be needed most. ${ }^{49}$ Thus, appropriate methods of data collection for the establishment of the HIF do not exist. Also, Selgelid systematically shows the problems that arise when the decline in GDB occurs due to effects caused by more than one drug. Based on counterfactual examples, he demonstrates that the actual effect of a drug is indefinable when there are synergistic or additive effects of a second drug. ${ }^{50} \mathrm{He}$ concludes that the evaluation of the real effect of a drug would require a huge amount of data collection and analysis in practice. Hence, an effective implementation of the HIF remains highly challenging and possibly unrealistic. $^{51}$
38 Pogge (2005: 192). In turn, Hollis (2008: 127) suggests a minimal commitment funding of 2 billion to 10 billion U.S. Dollars a year that would incentivize drug development and commercialization.

39 Through lower prices, a bigger quantity of medicines could be covered by the health care system and patients would have to spend less money on medicines (Pogge 2005: 192-193).

40 Pogge (2005: 193-194).

41 Pogge (2009: 548-550).

42 Hollis (2008: 126-127).

43 Pogge (2009: 549-550).
44 Hollis (2008: 128), Ravvin (2008: 121), Faunce and Nasu (2008: 150).

45 Hollis and Pogge (2008: 31).

46 Buchanan et al. (2008: 325-326).

47 Faunce and Nasu (2008: 150), Sonderholm (2010: 173).

48 Buchanan et al. (2008: 326).

49 Selgelid (2008: 138).

50 Selgelid (2008: 139-151), see Sonderholm (2010: 171-173).

51 Selgelid (2008: 138, 143). 


\section{An assessment of the HIF's ability to solve the access to medicine problem in the light of poverty traps}

So far, the presented critiques mainly address the implementation of the HIF. However, I will now focus in more detail on another practical problem - the "last mile problem" - that concerns access to pharmaceuticals. Many people are still excluded from drug use, although pharmaceuticals could be cheaply available. A recent UNAIDS report states that to this day only about 41 per cent of sub-Saharan African HIV/AIDS patients receive antiretroviral drugs. ${ }^{52}$ However, Sonderholm argues that antiretroviral HIV drugs are not commonly patented in African countries. ${ }^{53}$ Thus, the current TRIPS system cannot be made fully responsible for the exclusion of patients from essential drugs in the global AIDS crisis. According to Sonderholm, the lack of physicians, clinics, and infrastructure to administer the antiretroviral therapy and to screen people are the main causes for the AIDS epidemic and not the price policies of pharmaceuticals. ${ }^{54}$ This lack of infrastructure for the final distribution of drugs is known as the last mile problem. To reduce the global burden of disease effectively, drugs must be delivered to patients over 'the last mile'.

Hollis and Pogge argue that shortcomings in the health sector would adversely affect the spread of HIFregistered drugs. Hence, the authors believe that pharmaceutical companies that register drugs under the HIF would have strong incentives to sustainably pursue strategies to improve the health impact of new drugs on the GDB in order to increase the reward payments. ${ }^{55}$ Firms would tackle the last mile problem by improving factors that prevent the effective acquisition of drugs. ${ }^{56}$ Such improvements would be efforts to determine how information could be best communicated to the public, how health care education could be improved, and to identify strategies to encourage health care providers in the public and private sector to develop strategies for drug dispensers, health care workers and drug sellers. ${ }^{57}$ Furthermore, Pogge argues that HIF registrants, perhaps in collaboration with international agencies or NGOs, would be in a more potent position than poor countries to over-

52 UNAIDS (2013: 4). However, the provision of treatment in the area has been substantially increased during the last decade. As stated in a former WHO report (2005: 13), only 11 percent of the sub-Saharan African HIV patients received antiretroviral therapy in 2005 .

53 Sonderholm (2010: 170), see Attaran and Gillespie-White (2001).

54 Sonderholm (2010: 170-171) argues against Pogge (2005: 184) who uses the global AIDS crisis in Africa as vital example for the needs of poor patients that is played out against the recoup of $\mathrm{R} \& \mathrm{D}$ costs of pharmaceutical companies. come shortcomings on the last mile. ${ }^{58}$ Therefore, Hollis and Pogge consider the HIF as a realistic chance to improve the last mile problem.

However, as Sonderholm puts it, there is little hope that the HIF would sustainably solve the last mile problem. He argues that despite strong incentives to improve the access to medicines under the HIF, there would be a collective choice problem.

\section{"So, imagine that company $A$ has a product in country $x$ and that company $B$ also has a product in this country and that its product has a significantly higher potential for health improvement that the product of company $A$. Imagine also that company $A$ has another product in another country that has a huge potential for health im- provement and that company $B$ has no other product than the one it has in $\mathrm{x}$. [...] In this scenario, company A has very little financial incentive for contributing to country $\mathrm{x}^{\prime \prime 59}$}

In this outlined hypothetical case, a collective choice problem of lacking incentives to improve the health infrastructure occurs. Furthermore, assuming that there is usually more than one company that produces medicines with a potential health impact, firms would speculate to free-ride on the efforts made by other companies. This would eventually lead to a suboptimal provision of health infrastructure. ${ }^{60}$

Building upon Sonderholm's critique, I will introduce the concept of poverty traps and apply it to the last mile problem in order to provide a different, more fundamental critique of the HIF's ability to effectively solve the access to medicines problem. Similarly to Sonderholm, I do not believe that Hollis' and Pogge's argument - that firms would have the capacity to substantially contribute to the last mile problem ${ }^{61}$ - is very compelling. However, I believe that there are reasons other than the collective choice problem Sonderholm identifies. To show this, I will analyze the last mile problem in the context of global poverty traps.

The Millennium Development Goals (MDGs) established in 2000 envisaged the affluent countries mobilizing resources to reduce poverty by increasing develo-

55 Hollis and Pogge (2008: 75).

56 Hollis and Pogge (2008, Ch. 7).

57 Hollis and Pogge (2008: 75-77).

58 Pogge (2009: 549-550), Hollis and Pogge (2010).

59 Sonderholm (2010: 171).

60 As widely discussed in the economic theory of public goods, the free-rider problem occurs when those who benefit from goods do not pay for them, which results in a suboptimal provision of goods or services. See Cornes and Sandler (1996).

61 Hollis and Pogge (2008: Ch. 7). 
ping assistance from $0.25 \%$ of the gross domestic product in 2003 to $0.54 \%$ in 2015 which amounts to 120 billion U.S. Dollars annually. ${ }^{62}$ The goal was already exceeded by 2007 when more than 120 billion U.S. Dollars were spent, from which 22 billion U.S. Dollars were going to health programs. ${ }^{63}$

However, the United Nations, that set the MDGs, expected a much greater impact on poverty which was not overcome by the raising and spending of enormous funds. Many very poor countries are still unable to reach the outlined goals. For instance, according to estimates in 2010 and 2012, 896 million people were living on less than two Dollars a day. Child and maternal mortality are still above the target rate. ${ }^{64}$ David Stuckler et al. show that the unequal progress in achieving the health MDGs in low-income countries is significantly related to the burden of type I and type II diseases like HIV/AIDS and other communicable diseases. ${ }^{65}$

Gorik Ooms et al. explain that poverty traps are the major causes for the fact that the MDGs have not been met as expected. Poverty traps, according to Ooms et al., are vicious cycles of insufficient capital in which poor countries are unable to build up infrastructure and business, and to sustain education. This lack of sustainable infrastructure entails a lack of services that would be needed for health, education, or other basic infrastructure which, in turn, would be required to maintain the health of workers that would produce capital and so on. ${ }^{66}$ Poverty traps imply a long-term growth failure of very poor countries and an increasing divergence in the global economy. Also, institutional failures prevent countries from escaping this viscous cycle. ${ }^{67}$ Furthermore, global centres of economic growth and prosperity like the Western world, China, Russia, Brazil, and South Africa, attract capital and human resources to "bend the rules to their advantage", but the return of capital does not go back to poor countries. ${ }^{68}$ In addition to that, capital accumulation in poor countries can easily be overwhelmed by global price fluctuations, for instance, of commodities low-income countries largely depend on. Also, low-income countries frequently lack an insurance system that would be needed to develop comparative economic advantages. ${ }^{69}$
As Ooms et al. suggest, poor countries cannot improve their overall health situation due to the poverty traps they are caught in. In the following, I will show that this corresponds to the - what Sonderholm, Hollis and Pogge call - last mile problem. The failure to achieve the MDGs reveals the genuine importance of poverty traps and the substantial difficulties on the last mile, since countries remain in poverty despite the provision of enormous funding. Sustainable networks of services, staff and traffic systems that would be needed to efficiently solve the last mile problem seem to be deeply entangled with more far-reaching global economic structures. There are longstanding shortcomings like the lack of electricity, knowledge and information about diseases, as well as corruption which international agencies, NGOs and states have been addressing over several decades.

Given the entanglement of the last mile problem with global economic structures and local shortcomings, I argue that the HIF is not unable to solve the last mile problem just because of the collective choice problem Sonderholm introduces. Even if the presented collective choice problem could be solved, a sustainable intervention needed to drag a country out of a poverty trap would be too far-reaching in view of the local and global dimension of the trap. Despite the affluence of the pharmaceutical industry, it would be unlikely to expect private firms to have the necessary resources to attain success. This seems especially compelling when considering Hollis and Pogge's assumption that the resources needed to solve the last mile problem could almost exclusively be raised by the pharmaceutical industry. Then, the authors would have to claim that firms would maximize profits with the HIF while and precisely because they are freeing countries from poverty traps. This claim appears to substantially underrate the structural constitution of the last mile problem.

To actually tackle the access to medicines problem effectively, I suggest that the problem has to be viewed in a wider context of access to health-related information, knowledge, and education. ${ }^{70}$ These factors are of importance to the distribution of drugs, just as affordable prices. According to Thana Campos, only a fundamental institutional health reform could solve the current global
62 Ravishankar et al. (2009: 2113), see United Nations (2015), see Sachs and McArthur (2005).

63 Ooms et al. (2010: 1), see Ravishankar et al. (2009).

64 World Bank (2015), Stuckler et al. (2010: 2).

65 Stuckler et al. (2010: 1).

66 Ooms et al. (2010: 1-2).

67 Azariadis and John (2005).
68 Ooms et al. $(2010: 2)$.

69 Ooms et al. (2010: 3), see Lock et al. (2009).

70 See Campos (2008), see Balkin (2006) who defines access to knowledge as access to education, information, knowledge-embedded goods (products that require information for producing e.g. drugs) and tools for the reproduction of such goods. 
health dilemma. ${ }^{71}$ For instance, the Millennium Development Goals advocate a more systematic approach by identifying, for instance, pharmaceutical companies and the whole private sector as responsible actors to provide access to medicines and new technologies, such as information and communication technologies. ${ }^{72}$

\section{Conclusion}

The HIF is comprehensive in its scope and offers in its theoretical foundation a plausible mechanism to solve the health problems of the global poor. It is a serious attempt to tackle the global imbalance in $\mathrm{R} \& \mathrm{D}$ and to set long-term incentives for the development of cheap drugs with a global health impact. Thus, the HIF is a valuable reform proposal to address the problem of patentable drugs and the problem of extreme deprivation through monopoly prices. Also, the HIF is in line with a strong and justifiable ethical framework based on a human rights approach.
The critiques of the practical implementation I discussed suggest that more research on issues of practicality needs to be done before a final verdict on the HIF can be passed. However, having depicted the complex structures of poverty traps, the analysis of the last mile problem suggests that however positive this verdict turns out to be, the HIF' ability to solely improve the last mile problem is limited. In this regard, Hollis and Pogge may overestimate the potential strength of the HIF. Thus, I advocate an approach in which the HIF would be introduced as a mechanism alongside other structural reforms on a global and local level to overcome poverty traps and the access to medicines problem.

Felicitas Holzer absolviert zur Zeit das Masterprogramm (MPhil) in "History and Philosophy of Science" an der University of Cambridge mit den Schwerpunkten Bioethik und Wissenschaftstheorie. 
